Original Article

\title{
Clinical Safety of Laparoscopic Cholecystectomy in Elderly Patients: A Comparison of Clinical Outcomes in Patients Aged 65 to 79 Years and over 80 Years
}

\author{
Suhyun Kim, Namkyu Choi *, Minho Shin, Daesik Jung \\ Division of Hepatobiliary Surgery and Liver Transplantation, Department of Surgery, Chosun University Hospital, Gwangju, Korea
}

\section{Article history:}

Received: October 24, 2018

Revised: October 29, 2018

Accepted: October 30, 2018

\section{*Corresponding Author:}

Namkyu Choi

Division of Hepatobiliary Surgery and Liver

Transplantation, Department of Surgery,

Chosun University Hospital, Gwangju, Korea

E-mail:cnk@chosun.ac.kr

\section{ORCID}

Suhyun Kim

https://orcid.org/0000-0001-8338-4254

Namkyu Choi

https://orcid.org/0000-0003-0726-1353

Minho Shin

https://orcid org/0000-0001-9706-4366

Daisik Jeong

https://orcid.org/0000-0002-5293-7933

\section{ABSTRACT}

Purpose: The safety and efficacy of laparoscopic cholecystectomy (LC) in elderly patients is a matter of concern because morbidity and clinical risk are higher in elderly patients; and some clinicians recommend non-surgical supportive treatments. There is limited data reported in the literature for LC in super-elderly individuals (aged $\geq 80$ years). This study compared the clinical outcome for the elderly and super-elderly patients undergoing LC.

Methods: Patients who had a cholecystectomy for acute or chronic cholecystitis, and empyema of the gall bladder between January 2011 and June 2018 were analyzed retrospectively. The clinical outcomes of the super-elderly patients ( $\geq 80$ years, Group 2 ) were compared with elderly patients (65-79 years, Group 1). Complications, conversion rate, postoperative hospital stays were assessed.

Results: The conversion rate was $5.5 \%$ and $8.4 \%$ in Groups 1 and 2 , respectively ( $p=0.749$ ). The surgical or medical complication rates were similar in both groups. A significant difference in operation time was observed between groups $(p<0.001)$. Although the super-elderly patients had longer postoperative hospital stays $(7.10 \pm 6.98)$ than the elderly patients $(4.60 \pm 6.06)$, there was no significant difference with between the 2 groups $(p=1.000)$.

Conclusion: The clinical outcomes of the conversion rate, complications, and mortality were similar in patients aged 65 to 79 years and $\geq 80$ years. Therefore, LC is deemed to be a safe and simple procedure for the super-elderly.

Keywords: aged, cholecystitis, laparoscopic cholecystectomy

\section{Introduction}

The incidence of acute cholecystitis (AC) increases with age, ranging from $20 \%$ to $30 \%$ among elderly individuals, and up to $80 \%$ among institutionalized elderly patients aged > 90 years. Furthermore, $>90 \%$ AC cases are closely associated with cholelithiasis [1]. A previous study has shown that the prevalence of gallstones and AC is correlated with age [2]. The standard treatment of AC is laparoscopic cholecystectomy (LC) in young adults [3]. However, the safety of LC for elderly patients remains controversial owing to them having increased comorbidity risks [4]. Reduced physiologic reserve increases the risk of morbidity and mortality in elderly patients. High rates of morbidity and mortality make it challenging for surgeons to select an optimal operative management strategy [5]. Thus, many clinicians considered percutaneous biliary drainage to avoid administration of general anesthesia and surgery [6]. However, there was no clinical evidence to support this concern. Recently, perioperative care for elderly patients and LC technique has been improved, which reduces the risk associated with LC. The demand of surgery for AC has increased, and thus there is a need to evaluate the clinical safety and efficacy of LC in super-elderly patients ( $\geq 80$ years) compared with elderly patients ( $\leq 65-79$ years). 


\section{Materials and Methods}

This study was retrospectively conducted with approval of Chosun University Hospital Ethics Review Committee (IRB no.: CHOSUN 2014-01-005). Medical records of patients who were aged $>65$ and had undergone LC between January 2011 and June 2018 were retrospectively analyzed. The patients were divided into 2 groups: Group 1 which comprised patients aged between 65 and 79, and Group 2 which comprised patients aged $\geq 80$ years. The American Society of Anesthesiologists (ASA) classification system was used as a functional measure for preoperative risk assessment [7].

Age, sex, ASA score and degree of severity of the 2 groups were based on the Tokyo guidelines (TG) 2018. Conversion rate, complications and operation time were compared between these 2 groups.

\section{Surgical procedure}

Under general anesthesia, a pneumoperitoneum was created by following Hasson technique and was insufflated with carbon dioxide gas. With the patient in the reverse Trendelenburg position with the left side down, a $10 \mathrm{~mm}$ trocar was inserted through an infra-umbilical incision for placing the telescope. A $5 \mathrm{~mm}$ trocar was inserted in the sub-xiphoid area, and a 5 $\mathrm{mm}$ trocar was inserted into the right subcostal area. The cystic duct and artery were exposed and clipped using a $5 \mathrm{~mm}$ clip. Hemostasis was achieved with electrocautery, and the resected specimen was removed via the infra-umbilical incision site using a protective plastic bag. Routine intraoperative cholangiography was not performed. Indication for conversion to open surgery were as follows; suspicion of common bile duct (CBD) injury, unidentified cystic duct due to severe inflammation, strong adhesion resulting from a previous abdominal surgery, severe active bleeding, large stone in CBD, or suspicion of gallbladder cancer.

\section{Statistical analysis}

Statistical analysis was conducted using IBM SPSS Statistics ver. 25.0 (IBM Co., Armonk, NY, USA).

Categorical variables were represented as mean values and ranges, and qualitative variables were described as frequency and percentage. One-way analysis of variance was used to assess differences in continuous variable between the 2 groups. The $\mathrm{p}$ values of less than 0.05 were considered to be statistically significant.

\section{Results}

A total of 613 patients were included in this study. There were 362 elderly patients (Group 1 ) aged $\leq 65-79$ years and 251 super-elderly patients (Group 2 ) aged $\geq 80$ years. Patient characteristics are described in Table 1. There were no differences in clinical characteristics, except for ASA scores, between the 2 groups of patients. There were a significantly higher number of patients with TG-grade III severity in Group 2 compared with Group 1 (Table 1).

Table 1 . Comparison of characteristics between relatively younger patients. Group 1 and super-aged patients (Group 2).

\begin{tabular}{lccc}
\hline Characteristic & Group I $(n=362)$ & Group II $(n=251)$ & $p$ \\
\hline Age $(y)$ & $72.42 \pm 4.29$ & $83.54 \pm 3.67$ & $<0.001$ \\
Male & $199(55.0)$ & $107(42.6)$ & 0.327 \\
Severity of AC & & & $<0.001$ \\
$\quad$ Grade I & $333(92.0)$ & $190(75.7)$ & \\
Grade II & $27(7.5)$ & $49(19.5)$ & \\
Grade III & $2(0.6)$ & $12(4.8)$ & $<0.001$ \\
ASA score & & $11(4.4)$ & \\
1 & $46(12.7)$ & $150(59.8)$ & \\
2 & $243(67.1)$ & $90(35.8)$ & \\
$\geq 3$ & $73(20.2)$ & & \\
\hline
\end{tabular}

Data are presented as mean \pm SD or $n(\%)$.

$\mathrm{AC}=$ acute cholecystitis, ASA = American Society of Anesthesiologists.

Table 2. Clinical outcomes of laparoscopic cholecystectomy.

\begin{tabular}{|c|c|c|c|}
\hline Variable & $\begin{array}{l}\text { Group } 1 \\
(n=362) \\
\end{array}$ & $\begin{array}{l}\text { Group } 2 \\
(n=251) \\
\end{array}$ & $p$ \\
\hline Conversion rate & $20(5.5)$ & $21(8.3)$ & 0.749 \\
\hline \multicolumn{4}{|l|}{ Surgical complications } \\
\hline Wound infection & $9(2.4)$ & $13(5.1)$ & 0.345 \\
\hline Hemangioma in GB fossa & $9(2.4)$ & $6(2.3)$ & 0.652 \\
\hline CBD injury & $10(2.7)$ & $4(1.5)$ & 0.732 \\
\hline $\begin{array}{l}\text { Intraoperative bleeding } \\
(\geq 200 \mathrm{ml})\end{array}$ & $10(2.7)$ & $22(8.7)$ & 0.603 \\
\hline Bowel injury & $4(1.1)$ & $3(1.2)$ & 0.453 \\
\hline \multicolumn{4}{|l|}{ Medical complications } \\
\hline Respiratory & $12(3.3)$ & $5(1.2)$ & 0.723 \\
\hline Gastrointestinal & $18(5.0)$ & $8(3.2)$ & 0.565 \\
\hline Renal & $8(2.2)$ & $3(1.2)$ & 0.876 \\
\hline Cardiovascular & $4(1.1)$ & $4(1.6)$ & 0.898 \\
\hline Other complications & $42(11.6)$ & $20(7.9)$ & 0.893 \\
\hline Operating times (min) & $57.43 \pm 29.54$ & $71.16 \pm 55.27$ & $<0.001$ \\
\hline Post op hospital stay (d) & $4.60 \pm 6.06$ & $7.10 \pm 6.98$ & 1.000 \\
\hline
\end{tabular}

Data are presented as mean \pm SD or $n(\%)$. $\mathrm{CBD}=$ common bile duct, $\mathrm{GB}=$ gallbladder 
A conversion from laparoscopic procedure to an open procedure was required in 20 patients (5.5\%) in Group 1, and 21 patients (8.4\%) in Group 2, but this difference was not significant ( $p=0.749$ ). There were no significant differences in rates of surgical complications including wound infection, hematoma in the gallbladder fossa, CBD injury, intraoperative bleeding, and bowel injury. Medical complications associated with respiratory, gastrointestinal, renal, and cardiovascular system were not different between the 2 groups. A significant difference was observed in the operation time between groups $(p<0.001$; Table 2).

A postoperative hospital stays was longer in Group 2 (7.10 \pm 6.98) than Group $1(4.60 \pm 6.06)$, but this difference was not significant $(p=1.000$; Table 2$)$.

\section{Discussion}

The definitive treatment for AC is LC. However, LC in elderly patients has high perioperative risks. Therefore, some physicians prefer conservative treatment for AC in elderly patients, which includes the use of antibiotics or biliary drainage [8]. Several studies have shown that biliary drainage for AC can be easily and successfully performed. However, uncontrolled AC has a risk of cholangitis, septic shock, and even death. Moreover, biliary drainage is uncomfortable for patients and leads to a low quality of life $[1,5,6,9]$.

Some studies show that LC is a feasible and safe treatment option for elderly patients [7-9]. Most of these studies have compared outcomes of this procedure in patients $\geq 65$ years old with those in younger patients, and only a few studies have compared the outcomes of super-elderly and elderly patients. This current study focused on the feasibility of LC for AC in super-elderly individuals.

TG severity grading reportedly plays an important role in the outcome of LC [10] and open conversion cholecystectomy is also an important factor [11,12]. The factors affecting the outcome of LC increase postoperative complications, mortality rates, and length of hospital stay, leading to economic losses [13]. Therefore, it was determined whether these identified risk factors directly affected the clinical outcome of the 2 groups of patients.

In this current study, the males in Group 1 showed a high conversion rate, similar to findings reported by Ambe and Köhler [14]. However, this was not the case for Group 2 patients. The super-elderly patients general condition was poor compared with the elderly patients, and had more comorbidities that led to higher ASA scores. Thus, ASA scores were used for measuring the performance status, and for predicting the risk related to LC surgery, consistent with the strategy adopted in previous studies $[7,15]$. For evaluating the severity of AC, TG grading system was followed [10], and it was observed that super-elderly patients frequently had higher ASA scores and TG grades compared with elderly patients. However, there was no significant difference between both groups in terms of ASA score or TG grade-associated clinical outcomes.

Open conversion procedures and increased operative times are important considerations in an elderly patient because they have a lower physiologic reserve and lack the ability to withstand long surgery times [11,12]. In this current study, the conversion rate was slightly higher in Group 2 patients which resulted in prolonged operation times, leading to a higher frequency of wound infections, and prolonged hospital stays. However, this difference observed between the 2 groups was not statistically significant.

Longer hospital stays increased the economic burden on patients, which was an important concern. We observed that patients with higher ASA scores and TG gradings had longer hospital stays, consistent with the findings reported in previous studies $[12,16]$. In both groups, it was observed that the duration of hospitalization was longer when the ASA score was higher. The relationship between the TG level and the prolonged hospital stays was more significant in the Group 2 patients. These results suggest that the severity of the $A C$ was more relevant to the clinical outcome than the patients' performance status as measured by AS scores in super-elderly patients.

Bile leakage is also an important concern that could result in sepsis caused by peritonitis. When CBD injury during the laparoscopic procedure was observed or suspected, the drainage tube was retained to monitor leakage. If bile leakage was observed, an endonasal biliary drainage was performed and complete recovery was achieved. In this study, we did not observe any significant bile leakage-associated complications that could affect postoperative morbidity and mortality. No significant difference in clinical outcomes was noted between the 2 groups.

Although the super-elderly patients had longer operation time and postoperative hospital stays than the elderly patients, there was no significant difference between the 2 groups with regards to complication rates and clinical outcomes.

This study had several limitations. The data of LC surgery performed by 3 surgeons at the same medical center were collected; however, the experience of each surgeon was not considered. This may have had an influence on the operating time, conversion rate, and clinical outcomes [13]. In addition, the differences in the overall health status and the incidence of accompanying diseases which were age related were not considered. Furthermore, cases of subtotal cholecystectomy or percutaneous drainage alone, which can be easily and safely applied to manage severe inflammatory AC were excluded [17]. Moreover, the long-term outcomes of LC according to patient 
quality of life as well as functionality and cost-effectiveness, were not analyzed [18]. In addition, the physiologic changes resulting from initiating a pneumoperitoneum (which is essential for the laparoscopic procedure under general anesthesia), may have caused significant impairment in cardiopulmonary function, but was not analyzed [19]. Furthermore, a significant bias existed in the selection of super-elderly patients for $\mathrm{LC}$ because the decision for operation was made by patients and their family members based on their general physical condition. This selective difference may have influenced a better hospital course and could have affected the results for the super-elderly patents.

In conclusion, bearing in mind the limitations of this study, and contrary to the perception that LC is not suitable for AC patients aged $\geq 80$ years, this study suggests that there is no significant difference in the clinical outcomes of LC surgery between elderly patients (aged 65-79 years) and superelderly patients (aged $\geq 80$ years). However, factors including comorbidities, performance status, and severity also need to be taken into consideration. Hence, avoidance of LC for AC in super-elderly patients is not mandatory if comorbidities are optimally managed and medical care is carefully provided during the perioperative course.

\section{Conflicts of Interest}

No potential conflict of interest relevant to this article was reported.

\section{Ethical Approval}

Chosun University Hospital Ethics Review Committee (IRB no: CHOSUN 2014-01-005).

\section{References}

[1] Kimura Y, Takada T, Strasberg SM, Pitt HA, Gouma DJ, Garden OJ, et al. TG13 current terminology, etiology, and epidemiology of acute cholangitis and cholecystitis. J Hepatobiliary Pancreat Sci 2013;20(1):8-23.
[2] Dubecz A, Langer M, Stadlhuber RJ, Schweigert M, Solymosi N, Feith M, et al. Cholecystectomy in the very elderly: Is 90 the new 70? J Gastrointest Surg 2012;16(2):282-5.

[3] Haltmeier T, Benjamin E, Inaba K, Lam L, Demetriades D. Early versus delayed same-admission laparoscopic cholecystectomy for acute cholecystitis in elderly patients with comorbidities. J Trauma Acute Care Surg 2015;78(4):801-7.

[4] Amir D, Amin N. Frequency of complications due to laparoscopic cholecystectomy in Hamedan Hospitals. J Pak Med Assoc 2012;62(1):13-5.

[5] Dimou FM, Adhikari D, Mehta HB, Riall TS. Outcomes in older patients with grade III cholecystitis and cholecystostomy tube placement: a propensity score analysis. J Am Coll Surg 2017;224(4):502-11.e1.

[6] Kortram K, van Ramshorst B, Bollen TL, Besselink MG, Gouma DJ, Karsten $\mathrm{T}$, et al. Acute cholecystitis in high risk surgical patients: percutaneous cholecystostomy versus laparoscopic cholecystectomy (CHOCOLATE trial): Study protocol for a randomized controlled trial. Trials 2012;13:7.

[7] Visnjevac O, Davari-Farid S, Lee J, Pourafkari L, Arora P, Dosluoglu HH, et al. The effect of adding functional classification to ASA status for predicting 30-day mortality. Anesth Analg 2015;121(1):110-6.

[8] McGillicuddy EA, Schuster KM, Barre K, Suarez L, Hall MR, Kaml GJ, et al. Non-operative management of acute cholecystitis in the elderly. Br J Surg 2012;99(9):1254-61.

[9] Winbladh A, Gullstrand P, Svanvik J, Sandström P. Systematic review of cholecystostomy as a treatment option in acute cholecystitis. HPB (Oxford) 2009;11(3):183-93.

[10] Bouassida M, Chtourou MF, Charrada H, Zribi S, Hamzaoui L, Mighri MM et al. The severity grading of acute cholecystitis following the Tokyo Guidelines is the most powerful predictive factor for conversion from laparoscopic cholecystectomy to open cholecystectomy. J Visc Surg 2017;154(4): 239-43.

[11] Licciardello A, Arena M, Nicosia A, Di Stefano B, Calì G, Arena G, et al Preoperative risk factors for conversion from laparoscopic to open cholecystectomy. Eur Rev Med Pharmacol Sci 2014;18(2 Suppl):60-8.

[12] Paul Wright G, Stilwell K, Johnson J, Hefty MT, Chung MH. Predicting length of stay and conversion to open cholecystectomy for acute cholecystitis using the 2013 Tokyo Guidelines in a US population. J Hepatobiliary Pancreat Sci 2015;22(11):795-801.

[13] Morimoto Y, Mizuno H, Akamaru Y, Yasumasa K, Noro H, Kono E, et al Predicting prolonged hospital stay after laparoscopic cholecystectomy. Asian J Endosc Surg 2015;8(3):289-95.

[14] Ambe PC, Köhler L. Is the male gender an independent risk factor for complication in patients undergoing laparoscopic cholecystectomy for acute cholecystitis? Int Surg 2015;100(5):854-9.

[15] Lupei MI, Chipman JG, Beilman GJ, Oancea SC, Konia MR. The association between ASA status and other risk stratification models on postoperative intensive care unit outcomes. Anesth Analg 2014;118(5):989-94.

[16] Marcari RS, Lupinacci RM, Nadal LR, Rego RE, Coelho AM, de Matos Farah JF. Outcomes of laparoscopic cholecystectomy in octogenarians. JSLS 2012;16(2):271-5

[17] Ni Q, Chen D, Xu R, Shang D. The efficacy of percutaneous transhepatic gallbladder drainage on acute cholecystitis in high-risk elderly patients based on the Tokyo Guidelines: A retrospective case-control study. Medicine (Baltimore) 2015;94(34):e1442.

[18] Brauer DG, Hawkins WG, Strasberg SM, Brunt LM, Jaques DP, Mercurio $\mathrm{NR}$, et al. Cost variation in a laparoscopic cholecystectomy and the association with outcomes across a single health system: implications for standardization and improved resource utilization. HPB (Oxford) 2015;17(12):1113-8.

[19] Galizia G, Prizio G, Lieto E, Castellano P, Pelosio L, Imperatore V, et al. Hemodynamic and pulmonary changes during open, carbon dioxide pneumoperitoneum and abdominal wall-lifting cholecystectomy. A prospective, randomized study. Surg Endosc 2001;15(5):477-83. 